\title{
INGENIERÍA CIVIL
}

\begin{tabular}{|c|l|c|}
\hline Estudiante & \multicolumn{1}{|c|}{ Proyecto } & Asesor \\
\hline $\begin{array}{c}\text { Dovid Morales } \\
\text { Paola Villamil }\end{array}$ & $\begin{array}{l}\text { Análisis a flexión y corte en maderas } \\
\text { tipo Perillo y Otobo. }\end{array}$ & Luis Ernesto Gómez \\
\hline $\begin{array}{c}\text { Ximena Cháves } \\
\text { Sandra Poveda } \\
\text { Wilmar Zapata }\end{array}$ & $\begin{array}{l}\text { Asfalto y sus aplicaciones en } \\
\text { Colombia. }\end{array}$ & Lilian Meza \\
\hline July Alexandra Daza & $\begin{array}{l}\text { Diseño e instalación de un ensayo para } \\
\text { realizar pruebas de cavitación hidrodi- } \\
\text { námica (modelo experimental). }\end{array}$ & Cristian Villanueva \\
\hline $\begin{array}{c}\text { Fredy Arias } \\
\text { Carlos Andrés } \\
\text { Salamanca } \\
\text { José Muñoz }\end{array}$ & $\begin{array}{l}\text { Implementación de los análisis de la- } \\
\text { boratorio necesarios para verificar la } \\
\text { calidad del agua potable en la mini- } \\
\text { planta de tratamiento de sedimentos } \\
\text { en la sede Carlos Acosta. }\end{array}$ & Camilo Torres \\
\hline Yadira Gómez & $\begin{array}{l}\text { Estado del arte en el control (com- } \\
\text { puertas) de alcantarillados para evitar } \\
\text { inundaciones en picos de creciente. }\end{array}$ & Lilian Meza \\
\hline Giovanni Correa & $\begin{array}{l}\text { Estudio de vulnerabilidad sísmica del } \\
\text { edificio Carlos Acosta. }\end{array}$ & Wilson Mafla \\
\hline Maximiliano Villadiego & $\begin{array}{l}\text { Medida del equivalente de arena en } \\
\text { las diferentes canteras de la sabana } \\
\text { Ricardo Bónchezota. }\end{array}$ & Wilson Mafla \\
\hline
\end{tabular}

\section{TECNOLOGÍA EN ELECTRÓNICA}

\begin{tabular}{|c|c|c|}
\hline Estudiante & Proyecto & Asesor \\
\hline Helbert Baracaldo & $\begin{array}{l}\text { Sistema electrónico de segu- } \\
\text { ridad en automóviles: Auto } \\
\text { Seg Programador. }\end{array}$ & $\begin{array}{c}\text { Diego Cano } \\
\text { John William Vásquez }\end{array}$ \\
\hline $\begin{array}{l}\text { Didier Carpeta } \\
\text { José Ramírez }\end{array}$ & $\begin{array}{l}\text { Banco Variador electrónico } \\
\text { de Velocidad de motores } \\
\text { trifásicos. }\end{array}$ & Diego Ramos \\
\hline $\begin{array}{l}\text { Daniel Cubillos } \\
\text { Luis Robayo }\end{array}$ & $\begin{array}{l}\text { Medidor Electrónico de pH } \\
\text { con interfaz USB. }\end{array}$ & Diego Cano \\
\hline $\begin{array}{l}\text { Ferleín González } \\
\text { Jorge Noreña }\end{array}$ & $\begin{array}{l}\text { Interfaz Haptica entrenador } \\
\text { manejo de vehículos. }\end{array}$ & Diego Cano \\
\hline $\begin{array}{l}\text { Juan Laverde } \\
\text { Lisandro Moreno }\end{array}$ & $\begin{array}{l}\text { Planta piloto selectora au- } \\
\text { tomática de partículas por } \\
\text { color. }\end{array}$ & $\begin{array}{c}\text { Diego Ramos } \\
\text { John William Vásquez }\end{array}$ \\
\hline $\begin{array}{c}\text { Néstor Beltrán } \\
\text { Ayinson San Miguel }\end{array}$ & $\begin{array}{l}\text { Sistema electrónico para la } \\
\text { medición de espesores por } \\
\text { efecto Hall. }\end{array}$ & Giovani Baquero \\
\hline Jhonatan Alvarez & $\begin{array}{l}\text { Transformada rápida de Fu- } \\
\text { rier. Solución económica ba- } \\
\text { sada en PIC. }\end{array}$ & Diego Cano \\
\hline
\end{tabular}

